\title{
Editorial
}

\section{Inquiries into commissions of inquiry into police}

Commissions of inquiry into police have a long and chequered history - both internationally and locally. In this special edition, our focus falls on the two most recent commissions of inquiry into police in South Africa parochially known as the Marikana and Khayelitsha commissions. The deliberations of the two commissions have attracted much attention. Media coverage has at times opted for the sensational. However, a steady stream of more thoughtful commentaries, crafted by investigative journalists and policing experts, has also seen the light. The archival footprints of both commissions have been enormous. Thousands of pages of information on a wide range of administrative, operational and policy matters of relevance to police and policing have been produced. The online storage of expert testimonies, witness statements, and transcriptions of cross-examinations has further enhanced access to both primary and secondary material. Amid this abundance of data it would seem that those interested in the trials and tribulations of policing the post-colony can do no better than to capitalise on the opportunity for critical reflection and substantive analysis. In this special edition of the South African Crime Quarterly we take up the challenge for reflection.

Commissions of inquiry in their own right constitute suitable objects for inquiry. For example, commissions constitute rich topics for historical inquiry. Turning to South Africa, the historical record reveals a number of major inquiries that have been established in response to a wide range of concerns ever since the establishment of the modern South African state in 1910. With the benefit of hindsight it is evident that the Marikana and Khayelitsha commissions constitute contemporary variations on a much larger theme of public inquiries into police.

Commissions of inquiry yield themselves to comparative analysis; applied to commissions across time and space, a comparison allows us to identify commonalities and differences between public inquiries. Commissions share some generic features: they are first and foremost mechanisms of investigation; they are endowed with legal capacity and project an image of impartiality. All commissions collect material, call witnesses to testify, and make use of expert evidence. They exhibit considerable diversity, with terms of reference that can vary from the bold and ambitious to the narrow and restrained. Commissions may be backward looking or future orientated. They can conduct their business in both investigatory and inquisitorial manners. The recommendations they formulate may aim at larger systemic changes or focus on mere technical adjustments.

Commissions are suitable objects for sociological and political inquiry. Being constitutive of social and political interests, commissions can become sites for contestations between interest groups. Commissions fulfil a host of symbolic functions; they provide signals that a government is acting in response to issues of concern, thus offering opportunities for legitimating state power. Conversely, they may defy simplistic attempts to depict them as mere instruments to be manipulated at will by the executive. Commissions provide opportunities for learning (retrospectively) and for innovation (proactively). Do commissions make a difference? It depends. The research record suggests that impact is shaped by a wide variety of factors and that there is no guarantee that the findings and recommendations will change the course of organisational life.

Finally, public inquiries can be read as forms of political dramatisations where actors convene in a theatrical space to engage on issues of public importance. The casts consist of judges, legal teams, experts, witnesses and audiences. The scripts follow a particular logic. Dramaturgical analysis, in the good tradition of Erving Goffman, allows us to look beyond the surface of who said what, and to whom. It provides us with a 'backstage pass' to the rules of engagement around which roles and relationships are structured, narratives develop and 'truth claims' are made. 
Making sense of the deliberations to which commissions give rise is a challenging undertaking. As objects of study, commissions can be 'read' in many different ways, as the articles included in this edition illustrate.

In the first article, Bill Dixon brings a comparative angle to bear. He chooses two commissions from very different jurisdictions (Brixton, United Kingdom, and Khayelitsha, South Africa) to explore how and to what extent these commissions have engaged the social context within which police invariably operate. He raises interesting questions relating to the imperative for situating police in context and the constraints on commissions to engage the structural context in their recommendations for change.

The next two articles are situated squarely within the deliberations of the Khayelitsha Commission of Inquiry. Capitalising on the administrative data relating to resource allocation, revealed in minute detail by this commission, Jean Redpath and Fairouz Nagia-Luddy recap the flaws in the theoretical model and go on to offer an alternative for the allocation of resources, one based on the 'burden' that policing confronts in any particular locality. Failure to engage resource allocation, rationally and ethnically, will simply mean the perpetuation of structural inequities undermining access to resources in precincts that are inhabited by the urban poor.

The Khayelitsha Commission has been criticised for its singular focus on the police. Laura Freeman and Claire McDonald zoom outwards from the police organisation in Khayelitsha. Here, they map the intricate web of linkages, associations and interactions that characterise the field of policing. What needs to be appreciated is that the SAPS occupies a place within a wider and complex network of associations and structures. There is considerable variation in the nature of those relationships, whether cooperative, competitive, subservient or conflictual. Policing, we are reminded, is a complex relational endeavour. Efficiency in the police organisation thus remains dependent, at least in part, on efficiency elsewhere in the web.

Gareth Newham undertakes a critical reading of the public inquiry into the fateful Marikana events. His gaze is focused - squarely and uncompromisingly - on the senior leadership of the organisation, rather than those police who were deployed at the platinum mine in August 2012. He finds the upper echelons of the organisation deeply compromised and starkly politicised. They have reneged on the democratic principles of professional, non-partisan and ethical leadership. Deliberate attempts to obfuscate the commission's work provide tangible proof of a senior leadership that no longer abides by the principles of ethical professionalism. On the available evidence, it would thus appear that the project of democratic policing is effectively being sabotaged from the top.

Commissions are external, independent and public forms of inquiry. Extensive and often dramatised media coverage puts their deliberations at the centre of public debate. But in the life of organisations, other forms of investigation of a more internal nature are part of routine stocktaking. Johan Burger reminds us that there has been no shortage of reviews of the organisational aspects of policing in recent years. Such reviews expose a considerable convergence in the findings related to administrative and operational failures, all constituents in the gamut of systemic challenges confronting the police organisation. The vexing question is not what is wrong - but rather why, in the face of agreement about key systemic failures, there is such a glaring lack of concerted effort to address them.

We conclude this special edition with a conversation with Judge Kate O'Regan, who together with Advocate Vusi Pikoli headed the Khayelitsha inquiry. In this conversation she speaks to the principles and processes that guided the work of the commission, the testimonies received, the huge challenges confronting police in a high crime and resource hungry locality, and the responsibility on the state to engage shortcomings in the system.

\section{Elrena van der Spuy}

\section{Centre of Criminology, Faculty of Law at the University of Cape Town}

Elrena.vanderspuy@uct.ac.za 